\title{
Predicting 1-Year Statin Adherence Among Prevalent Users: A Retrospective Cohort Study
}

\author{
Alexis A. Krumme, MS; Jessica M. Franklin, PhD; Danielle L. Isaman, BS; \\ Olga S. Matlin, PhD; Angela Y. Tong, MS; Claire M. Spettell, PhD; Troyen A. Brennan, MD, JD, MPH; \\ William H. Shrank, MD, MSHS; and Niteesh K. Choudhry, MD, PhD
}

\begin{abstract}
BACKGROUND: Attempts to predict who is at risk of future nonadherence have largely focused on predictions at the time of therapy initiation; however, these users are only a small proportion of all patients on therapy at any point in time. Methods to predict nonadherence for established medication users, which have not been previously described in the literature, would be helpful to guide efforts to enhance the use of evidence-based therapies.
\end{abstract}

OBJECTIVE: To test approaches for adherence prediction among prevalent statin users, namely the use of short-term filling behavior, investigatorspecified predictors from medical and pharmacy administrative claims, and the empirical selection of potential predictors using the high-dimensional propensity score variable selection algorithm.

METHODS: Medical and prescription claims data from a large national health insurer were used to create a cohort of patients who filled statin medication prescriptions in January 2012. We defined 6 groups of adherence predictors and estimated 10 main models to predict medication adherence in the full cohort. The same was done for the population stratified based on the days supply of the index statin prescription ( $\leq 30$ days vs. $>30$ days).

RESULTS: The study cohort consisted of 93,777 individuals, $58.4 \%$ of which were adherent to statins during follow-up. The use of 3 pre-index adherence predictors alone achieved a c-statistic of 0.70 . Investigator-specified and empirically selected pharmacy, medical, and demographic variables did substantially worse (0.57-0.60). The use of 3 indicators of post-index adherence achieved a higher c-statistic than the best-performing model using pre-index information ( 0.74 vs. 0.72 ). The addition of 3 pre-index adherence predictors further improved discrimination (0.78).

CONCLUSIONS: This analysis demonstrated the ability to predict adherence among medication users using filling behavior before and immediately after an index prescription fill.

J Manag Care Spec Pharm. 2017;23(4):494-502

Copyright $\odot 2017$, Academy of Managed Care Pharmacy. All rights reserved.

\section{What is already known about this subject}

Among patients initiating therapy, models that rely on the observation of short-term filling behavior to predict adherence are substantially more accurate than more complex models using administrative health care databases.

Because adherence among prevalent users is dynamic, observations of short-term filling patterns may provide accurate predictions for more established users as well

\section{What this study adds}

Especially among patients with initial prescriptions of $\leq 30$ days supply, models that measured observed adherence before and after the follow-up period accurately discriminated adherent from nonadherent patients.

These models outperformed models with predictors selected through subject matter expertise and analytically complex models using high-dimensional predictors.

Adherence patterns may provide a simple and useful prediction tool for targeting patients with adherence interventions.

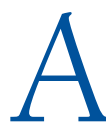
dherence to therapies that are essential for the effective management of cardiovascular disease remains low, with nearly half of patients becoming nonadherent within a year of starting therapy. ${ }^{1-3}$ Suboptimal adherence to these medications results in substantial morbidity, mortality, and avoidable health spending. ${ }^{4,5}$ While numerous interventions have been shown to improve medication-taking behaviors (e.g., the use of reminder devices or copayment waivers), the majority are only moderately effective. ${ }^{6-9}$ Better targeting of these interventions to those patients who are most likely to be nonadherent will almost certainly increase their effectiveness and efficiency.

Attempts to predict who is at risk of future nonadherence have largely focused on prediction at the time of therapy initiation. While "new initiators" represent a population that may be of particular interest, they are only a small proportion of all patients on a therapy at any given point in time. ${ }^{10}$ As a consequence, quality improvement interventions aimed at improving adherence, such as the Medicare star ratings, which are a critical part of Part D reimbursement, usually consider all patients on therapy and not only those who have newly initiated therapy. ${ }^{11}$ Further, these programs generally take the perspective of a defined period of calendar time, rather than time relative to when a patient starts treatment. Therefore, methods to predict nonadherence for established medication users, which have not been previously described in the literature, are needed to guide efforts to enhance the use of evidence-based therapies.

Models that rely on the observation of short-term filling behavior to predict adherence have been shown to be 
substantially more accurate than traditional health care claimsbased approaches or even more complex models using large numbers of empirically selected predictors among patients starting therapy for the first time. ${ }^{12}$ Because adherence among prevalent users may also be dynamic, observations of shortterm filling patterns may provide accurate predictions for more established users as well. ${ }^{13}$

Accordingly, in this analysis, we applied the approach of predicting adherence using short-term filling behavior in new users to a population of prevalent statin users at the beginning of a calendar year. We compared performance to that of other health care claims-based approaches, including variables from pharmacy and medical claims. Within each of these data sources, we compared the discriminative ability of investigatorspecified covariates to the empirical selection of potential adherence predictors through the high-dimensional propensity score (hd-PS) variable selection algorithm. ${ }^{14,15}$

\section{Methods}

\section{Study Setting and Cohort}

We used a limited dataset of medical and prescription claims data for commercial, fully insured members of Aetna, a large national health insurer, to create a cohort of patients who filled statin medication prescriptions in January 2012. Patients were required to have continuous enrollment in medical and pharmacy benefits from July 2011 through at least December 31, 2012. We defined "prevalent" use as having at least 1 statin fill between July and December 2011. The date of a patient's first prescription in January 2012 was defined as the index date.

The data contained complete paid claims for all procedures, physician encounters, hospitalizations, and filled prescriptions (including dose dispensed and amounts paid by the insurer and patient) and were linked to eligibility data that included patient age, gender, and ZIP code of residence. Aggregate data on socioeconomic status, race/ethnicity, and educational attainment were obtained by linking the ZIP code of residence with data from the 2010 U.S. Census, which specified the median household income as well as the distribution of race/ ethnicity and educational attainment of the population for each ZIP code tabulation area. The Institutional Review Board of Brigham and Women's Hospital approved this study.

\section{Adherence Measures}

We followed patients and recorded fills for prescriptions of any statin for the 2012 calendar year. For each patient, we created a supply diary that indicated whether each day was covered with medication by linking all observed statin fills based on the dispensing date and the days supply. Based on the supply diary, we calculated the proportion of days covered (PDC) as the number of days a patient had a statin supply available divided by the number of days from the date of index statin prescription through December 31, 2012. We defined "full adherence" as $\mathrm{PDC} \geq 0.8$, which corresponds to the level of use above which patients with coronary artery disease benefit from statins and is the threshold used by most quality measures. ${ }^{16,17}$ Nonadherence was defined as $\operatorname{PDC}<0.8 .^{11,18}$

\section{Predictors of Adherence}

The following 6 groups of adherence predictors were defined.

1. Investigator-Specified Pharmacy and Demographic Predictors. Sixteen covariates were defined using pharmacy claims incurred in the 180 days before and including the index prescription. These covariates included information on the index statin fill, such as generic name, patient out-of-pocket spending amount, days supply, and statin dose intensity. We also included indicators for the presence of maintenance medications for 11 chronic conditions (coronary artery disease, hypertension, diabetes, congestive heart failure, COPD/asthma, depression, bipolar disorder and anxiety, osteoporosis, arrhythmia, and hyperlipidemia) and the total number of chronic disease medications taken. Demographic covariates included patient age and gender, race, education level, and median income in ZIP code of residence.

2. Pre-index Adherence. Three predictors were constructed based on adherence in the 180 days before January 1, 2012. First, we evaluated previous adherence to statins as the PDC from the first statin prescription in the pre-index period until the index date. Second, patients with a gap in days supply that was longer during the 90-day period immediately before the index date were defined as having declining adherence. Third, we calculated PDC for all chronic disease medications with the exception of medications to treat bipolar disorder, anxiety, and depression, which are not necessarily intended for lifelong use, and classified patients according to whether they were fully adherent to more or less than $50 \%$ of their medications. ${ }^{19}$ Patients taking none of these medications were modeled as a separate category.

3. Investigator-Specified Medical Predictors. Thirty-one covariates were defined using medical claims incurred in the 180 days before the index date. These included measures of morbidity and health service use, such as the Charlson Comorbidity Index, the number of cardiovascular diagnoses, hospitalizations and total length of stay, and physician visits. Indicators were also included for the presence of individual cardiovascular and other chronic disease comorbidities and use of preventive health services, such as influenza vaccination, that may be indicative of adherence.

4. Pharmacy Claims High-Dimensional Propensity Score. The pharmacy claims high-dimensional propensityscore(hd-PS) algorithm was used to identify a large collection of variables available in pharmacy claims that could proxy for underlying behavioral constructs predictive of adherence. ${ }^{14,15}$ This 
algorithm was originally developed to improve confounding control by screening thousands of medication codes for an empirical association with the study exposure of interest, of which the top 300-500 are selected. These variables have been shown to collectively proxy for important patient-level characteristics that are unmeasured in administrative claims databases. We applied the hd-PS algorithm to all pharmacy claims within 180 days before the index date to select the 400 medication codes with the strongest associations with full adherence. ${ }^{12}$

5. Medical Claims High-Dimensional Propensity Score. The hd-PS variable selection algorithm was also applied to diagnosis and procedure codes from medical claims from the 180 days before the index date, selecting the 400 diagnosis codes with the strongest associations with full adherence.

6. Post-index Medication Filling. Three indicator variables (PDC $\geq 0.8$ or $\geq 24$ days covered, equivalently) were created to capture medication filling during each of the first three 30-day periods after index prescription fill. These methods have been described elsewhere. ${ }^{12}$

\section{Statistical Analysis}

Ten main prediction models were estimated in the full cohort and in strata based on the days supply of the index statin prescription ( $\leq 30$ days vs. $>30$ days). All prediction and evaluation was performed in SAS version 9.3 (SAS Institute, Cary, NC).

Models 1-4 used only pharmacy claims-based predictors, both investigator specified and selected by the hd-PS algorithm, while models 5 and 6 used only medical claims-based predictors. Model 7 used all pharmacy and medical claims predictors together. Model 8 included only the 3 postadherence indicators. Models 9 and 10 evaluated the incremental improvement of post-index adherence indicators in conjunction with the previously mentioned predictors. Other combinations of predictors were also evaluated, results of which are presented in Appendix A (available in online article). All models excluded the $2.3 \%$ of patients with missing data for census-derived variables.

We evaluated the effect of these approaches using c-statistics that quantify model prediction accuracy as applied to a new set of patients. ${ }^{20}$ This measure ranges from 0.5 to 1.0, corresponding to a completely noninformative model and perfect prediction, respectively. ${ }^{21}$ Ten-fold cross-validation was performed to avoid bias associated with evaluating prediction accuracy in the same data that were used for model estimation. ${ }^{22}$

Several analyses were also conducted to evaluate whether the same set(s) of predictors achieved optimal prediction results in different periods of follow-up. First, we conducted the same analysis on a cohort of patients with a statin prescription in May 2012, using a time frame shifted forward by 4 months. This analysis evaluated whether predictive ability was affected by a calendar year effect, in which patients have different adherence patterns in a January to December interval as compared with a different 12-month interval. Second, because models using post-index adherence indicators include 3 months of the adherence outcome, a sensitivity analysis was conducted in which we measured the adherence outcome during April through December 2012 to exclude temporal overlap between predictors and outcome.

\section{Results}

\section{Patient Characteristics}

The study cohort consisted of 93,777 individuals who filled a statin in January 2012 and who had also filled a statin in the previous 180 days. Approximately $85 \%$ of the cohort had an index fill with $\leq 30$ days supply (Table 1 ). Members of the cohort were more likely to be male (60.5\%), were aged approximately 57 years, and most lived in ZIP codes with median annual incomes of $\$ 50,000-\$ 100,000$ (64.9\%). The most common medical comorbidities were hypertension (41.4\%), diabetes (14.9\%), and coronary artery disease (10.3\%). During the 180 days before the index date, approximately two thirds (69.5\%) of patients were fully adherent to their statin medications, and almost a quarter $(22.5 \%)$ of patients exhibited declining statin adherence. More than three quarters of patients (76.8\%) were taking at least 1 nonstatin chronic disease medication at baseline, and two thirds of these patients were adherent to more than half of their medications.

During follow-up, $58.4 \%$ of the cohort was adherent to statins. Adherence was higher for patients who filled $a \leq 30$-day supply compared with a $\leq 30$-day supply at index fill $(70.4 \%$ vs. $56.3 \%)$.

\section{Prediction Accuracy}

Results of the predictive models are shown in Table 2. The use of 3 pre-index adherence predictors alone achieved a c-statistic of 0.70. Investigator-specified pharmacy and demographic variables and variables selected by the hd-PS algorithm did substantially worse (0.60, both models). The predictive accuracy of variables derived from medical claims, both investigator specified and empirically selected by the hd-PS algorithm, was also poor ( 0.57 , both models). Medical covariates also did not add substantially to discriminative ability of models based on pharmacy claims ( 0.71 for pharmacy covariates vs. 0.72 for pharmacy and medical covariates). The use of 3 indicators of post-index adherence achieved a higher c-statistic than the best-performing model using pre-index information ( 0.74 vs. 0.72). The addition of pre-index adherence predictors further improved discrimination, and the subsequent addition of all pharmacy and medical covariates had only a small effect on the c-statistic (0.78 vs. 0.79).

After stratifying by the length of the index prescription, model c-statistics in patients with a supply of $\leq 30$ days were 
TABLE 1 Cohort Baseline Characteristics

\begin{tabular}{|c|c|c|c|c|c|c|c|}
\hline \multirow[b]{2}{*}{ Characteristic $^{a}$} & \multirow[b]{2}{*}{$\begin{array}{l}\text { Full Cohort } \\
(\mathrm{N}=93,777)\end{array}$} & \multicolumn{2}{|c|}{ Days Supply of Index Statin } & \multirow[b]{2}{*}{ Characteristic $^{\mathrm{a}}$} & \multirow[b]{2}{*}{$\begin{array}{l}\text { Full Cohort } \\
(\mathrm{N}=93,777)\end{array}$} & \multicolumn{2}{|c|}{ Days Supply of Index Statin } \\
\hline & & $\begin{array}{l}\leq 30 \text { Days } \\
(\mathrm{n}=79,411)\end{array}$ & $\begin{array}{l}\text { > } 30 \text { Days } \\
(\mathrm{n}=14,366)\end{array}$ & & & $\begin{array}{l}\leq 30 \text { Days } \\
(\mathrm{n}=79,411)\end{array}$ & $\begin{array}{l}\text { >30 Days } \\
(\mathrm{n}=14,366)\end{array}$ \\
\hline \multicolumn{4}{|l|}{ Demographics } & \multicolumn{4}{|c|}{ Pharmacy data } \\
\hline Female & 39.5 & 39.8 & 37.7 & \multicolumn{4}{|c|}{ Chronic disease medication adherence ${ }^{c}$} \\
\hline Age, mean (SD) & $57.3(9.1)$ & $56.9(9.0)$ & $59.7 \quad(9.2)$ & Declining previous & 22.5 & 23.9 & 15.0 \\
\hline \multicolumn{4}{|c|}{ Median household income in ZIP code ${ }^{b}$} & statin adherence & & & \\
\hline Less than $\$ 50,000$ & 19.5 & 20.5 & 13.9 & \multicolumn{4}{|c|}{ Medical data } \\
\hline$\$ 50,000-\$ 99,999$ & 64.9 & 64.5 & 67.1 & \multicolumn{4}{|c|}{ Medical procedures and diagnoses, 180 days before index } \\
\hline$\$ 100,000+$ & 13.3 & 12.6 & 17.1 & Postsurgical aorto- & 0.8 & 0.8 & 1.1 \\
\hline \multirow{2}{*}{$\begin{array}{l}\text { Percentage of blacks in } \\
\text { ZIP code, mean (SD) }{ }^{\mathrm{b}}\end{array}$} & \multirow{2}{*}{$11.6(17.9)$} & \multirow{2}{*}{$11.5(17.8)$} & \multirow{2}{*}{$12.1(18.3)$} & coronary bypass & & & \\
\hline & & & & $\begin{array}{l}\text { Coronary artery } \\
\text { bypass graft surgery }\end{array}$ & 0.2 & 0.2 & 0.2 \\
\hline $\begin{array}{l}\text { Percentage with high } \\
\text { school education or } \\
\text { greater, mean (SD)b }\end{array}$ & $88.3(8.8)$ & $88.0 \quad(9.0)$ & $90.0 \quad(7.0)$ & $\begin{array}{l}\text { bypass graft surgery } \\
\text { Percutaneous coro- } \\
\text { nary intervention }\end{array}$ & 0.7 & 0.7 & 0.5 \\
\hline \multicolumn{4}{|l|}{ Pharmacy data } & Atrial fibrillation & 0.3 & 0.3 & 0.4 \\
\hline \multicolumn{4}{|l|}{ Index statin (generic) } & Chest pain & 5.8 & 5.9 & 5.6 \\
\hline Atorvastatin & 19.5 & 19.2 & 21.2 & Congestive heart & 0.1 & 0.1 & 0.1 \\
\hline Fluvastatin & 0.5 & 0.4 & 0.8 & failure & & & \\
\hline Lovastatin & 5.0 & 5.2 & 4.0 & Hypertension & 41.4 & 40.6 & 46.0 \\
\hline Pitavastatin & 0.4 & 0.4 & 0.3 & Coronary artery disease & 10.3 & 10.0 & 12.0 \\
\hline Pravastatin & 9.5 & 9.6 & 9.1 & Myocardial infarction & 0.2 & 0.3 & 0.1 \\
\hline Rosuvastatin & 17.8 & 17.7 & 17.9 & Peripheral vascular & 0.3 & 0.3 & 0.4 \\
\hline Simvastatin & 47.4 & 47.5 & 46.8 & & & & \\
\hline High-dose intensity & 32.3 & 32.1 & 33.9 & $\begin{array}{l}\text { Stroke or transient } \\
\text { ischemic attack }\end{array}$ & 0.7 & 0.7 & 0.6 \\
\hline $\begin{array}{l}\text { Copay index statin } \\
\text { prescription, mean (SD) }\end{array}$ & $\begin{array}{c}\$ 27.25 \\
(\$ 39.69) \\
\end{array}$ & $\begin{array}{c}\$ 23.47 \\
(\$ 30.55) \\
\end{array}$ & $\begin{array}{c}\$ 48.17 \\
(\$ 67.87)\end{array}$ & $\begin{array}{l}\text { Chronic obstructive } \\
\text { pulmonary disease }\end{array}$ & 2.7 & 2.7 & 2.7 \\
\hline \multicolumn{4}{|c|}{ Chronic disease medications, 180 days before index } & Alzheimer's disease & 0.3 & 0.3 & 0.3 \\
\hline 0 & 23.2 & 23.8 & 19.8 & or dementia & & & \\
\hline 1 & 36.2 & 36.3 & 35.4 & Depression & 4.3 & 4.4 & 4.0 \\
\hline 2 & 25.5 & 25.1 & 27.6 & Cancer & 9.0 & 8.6 & 11.5 \\
\hline 3 & 10.7 & 10.6 & 11.3 & Diabetes & 14.9 & 14.8 & 15.0 \\
\hline 4 & 3.4 & 3.2 & 4.3 & Kidney disease & 0.9 & 0.9 & 1.3 \\
\hline $5+$ & 1.1 & 1.1 & 1.5 & End-stage renal disease & 0.3 & 0.3 & 0.3 \\
\hline \multicolumn{4}{|c|}{ Chronic disease medication adherence $^{c}$} & \multirow{3}{*}{$\begin{array}{l}\text { Number of cardiovas- } \\
\text { cular diagnoses, mean } \\
\text { (SD) }\end{array}$} & \multirow[t]{3}{*}{$1.0(1.6)$} & \multirow[t]{3}{*}{$1.0(1.6)$} & $1.1(1.6)$ \\
\hline \begin{tabular}{l|} 
Adherent to most \\
\end{tabular} & 49.6 & 47.6 & 60.4 & & & & \\
\hline Adherent to some & 22.1 & 23.2 & 15.7 & & & & \\
\hline $\begin{array}{l}\text { Not taking any chronic } \\
\text { disease medications }\end{array}$ & 28.4 & 29.2 & 23.9 & $\begin{array}{l}\text { Number of hospitaliza- } \\
\text { tions, mean (SD) }\end{array}$ & $0.1(0.6)$ & $0.1(0.4)$ & $0.1(0.7)$ \\
\hline $\begin{array}{l}\text { Total number of } \\
\text { medications, mean (SD) }\end{array}$ & 5.8 (3.8) & $5.7(3.8)$ & $6.1 \quad(3.9)$ & $\begin{array}{l}\text { Number of physician } \\
\text { office visits, mean (SD) }\end{array}$ & $5.1(7.0)$ & $5.0(7.0)$ & $5.7(7.3)$ \\
\hline $\begin{array}{l}\text { Previous optimal adher- } \\
\text { ence (PDC } \geq 0.8 \text { ) to statins }\end{array}$ & 69.5 & 67.9 & 78.4 & $\begin{array}{l}\text { Charlson comorbidity } \\
\text { score, mean (SD) }\end{array}$ & $0.5(1.1)$ & $0.5(1.1)$ & $0.6(1.1)$ \\
\hline $\begin{array}{l}{ }^{a} \text { All values given as percen } \\
\text { bess than } 2 \% \text { of cohort mi } \\
\text { Among patients with at le } \\
\text { PDC = proportion of days }\end{array}$ & $\begin{array}{l}\text { res unless othe } \\
\text { ng values. }\end{array}$ & e indicated. & 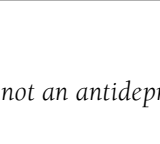 & or antipsychotic. & & & \\
\hline
\end{tabular}

generally higher than those in the entire cohort. Among patients who had a $>30$ days supply at the time of their first prescription, none of the models had c-statistics above 0.60 . Results from all other combinations of predictors are presented in Appendix A.

Table 3 presents multivariable results from the bestperforming model (Model 10), stratified by index days supply. Full adherence during each 30-day interval was strongly and significantly associated with full adherence at the end of the calendar year, as was full adherence in the 180day baseline period (odds ratio $[\mathrm{OR}]=2.69,95 \%$ confidence interval $[C I]=2.56-2.80$ for $\leq 30$ days supply; $O R=2.24,95 \%$ $\mathrm{CI}=2.04-2.45$ for $>30$ days supply). Being adherent to more than half versus less than half of chronic disease medications 
Predicting 1-Year Statin Adherence Among Prevalent Users: A Retrospective Cohort Study

\section{TABLE 2 Cross-Validated C-Statistics from 10 Models Measuring Prediction Accuracy During Follow-up}

\begin{tabular}{|c|c|c|c|c|}
\hline Model & Predictors & Full Cohort & $\leq 30$ Days Supply & $>30$ Days Supply \\
\hline 1 & Investigator-specified pharmacy and demographic & 0.60 & 0.60 & 0.56 \\
\hline 2 & Pre-index adherence & 0.70 & 0.71 & 0.59 \\
\hline 3 & Pharmacy claims hd-PS & 0.60 & 0.58 & 0.52 \\
\hline 4 & All pharmacy and demographic & 0.71 & 0.73 & 0.60 \\
\hline 5 & Investigator-specified medical & 0.57 & 0.57 & 0.56 \\
\hline 6 & Medical claims hd-PS & 0.57 & 0.57 & 0.55 \\
\hline 7 & All pre-index pharmacy, demographic, and medical & 0.72 & 0.73 & 0.60 \\
\hline 8 & Observation of post-index filling & 0.74 & 0.76 & 0.49 \\
\hline 9 & Pre-index adherence + observations of post-index filling & 0.78 & 0.80 & 0.60 \\
\hline 10 & All pre-index pharmacy, demographic, and medical + observation of post-index filling & 0.79 & 0.80 & 0.60 \\
\hline
\end{tabular}

was significantly associated with full adherence $(\mathrm{OR}=1.37,95 \%$ $\mathrm{CI}=1.31-1.43$ for $\leq 30$ days supply; $\mathrm{OR}=1.23,95 \% \mathrm{CI}=1.10-$ 1.37 for $>30$ days supply).

Figure 1 presents adherence outcomes by baseline statin adherence and post-index adherence patterns, separately by index days supply. In both groups, patients with high preindex statin adherence had higher rates of adherence compared with nonadherent patients. Among patients with $\leq 30$ days index supply, 58\% had full adherence during each of the first 3 months. Within this group, $79 \%$ went on to have full adherence in 2012. Based on these results, a prediction rule that identified patients as fully adherent if they had full coverage before the baseline period and nonadherent otherwise would have a positive predictive value (PPV) of $69 \%$ and a negative predictive value (NPV) of $71 \%$ in patients with index supply $\leq 30$ days. A prediction rule depending on coverage before the baseline period and during months 1 and 2 after baseline would have a PPV of $75 \%$ and an NPV of $67 \%$.

Among patients with $>30$ days index supply, 98\% had complete coverage during each of the first 3 months. Of these, 75\% went on to have full adherence in 2012 compared with only $55.6 \%$ of patients who were not adherent in the pre-index period.

\section{Sensitivity Analyses}

Results from a cohort of prevalent statin users with index dispensing in May 2012 are shown in Appendix B (available in online article). This cohort consisted of 66,003 members, $55 \%$ of whom were fully adherent at the end of April 2013. C-statistics were slightly higher but generally consistent with those in the January cohort. The results of the main analysis were unchanged after adjusting the adherence outcome to exclude the time period in which post-index adherence indicators were measured.

\section{Discussion}

In a cohort of over 90,000 prevalent users of statins, we found that models using measures of observed adherence, both before and after the beginning of follow-up, accurately discriminate adherent from nonadherent patients, especially among those with initial prescriptions of $\leq 30$ days supply. Further, these models outperform models with predictors selected through subject matter expertise and even analytically complex models using high-dimensional predictors. Our results extend an approach that has been demonstrated to be accurate among new initiators to a much larger cohort of established users and illustrate the ability to apply these predictions to a cohort based on calendar time, rather than on time relative to medication initiation, which may ultimately be more useful for quality improvement efforts and targeting resources to those most likely to benefit. ${ }^{12}$

The ability to identify patients who are likely to become nonadherent despite being established on therapy lends support to the concept that adherence is not only a dynamic process, but also one with predictable patterns of fluctuation over the course of a patient's lifetime on treatment. Similar to findings in other health domains, such as diet and exercise, these results suggest that to be maximally effective, adherence improvement interventions must provide ongoing support rather than outreach at a single point in time. ${ }^{23-25}$

The similarity of findings from this analysis with those reported for new users suggests that behaviors exhibited at treatment initiation may be similar to those observed later in a patient's treatment course and just as powerful at predicting future adherence. It is possible that a cohort of prevalent users based on medication filling in January may be similar in behavior to new users through a recommitment-type mechanism at the start of a new calendar year ${ }^{26}$; however, similar results from a sensitivity analysis with the follow-up time frame shifted forward by 4 months suggested that our cohort was not substantially different from any other group of prevalent users. Longitudinal adherence trajectories, an approach in which individuals are grouped according to their prescriptionfilling patterns over time, may shed light on the similarities in longer-term filling behaviors across these 2 types of users. ${ }^{27}$ 
Predicting 1-Year Statin Adherence Among Prevalent Users: A Retrospective Cohort Study

TABLE 3 Odds Ratios and 95\% Cls from Model 10, Separately Within Each Stratum of Days Supply

\begin{tabular}{|c|c|c|c|c|c|}
\hline Characteristic & $\leq 30$ Days Supply & > 30 Days Supply & Characteristic & $\leq 30$ Days Supply & >30 Days Supply \\
\hline Adherent month 1 & $2.43 \quad(1.41-4.19)$ & $\mathrm{a}$ & Number of cardiovascular diagnoses & $0.99 \quad(0.97-1.01)$ & $1.01 \quad(0.97-1.05)$ \\
\hline Adherent month 2 & $3.22(3.10-3.35)$ & $3.23(1.28-8.16)$ & Charlson comorbidity score & $1.01 \quad(0.99-1.04)$ & $1.01 \quad(0.96-1.05)$ \\
\hline Adherent month 3 & $4.65 \quad(4.47-4.84)$ & $2.65(1.98-3.56)$ & Number of hospitalizations & $1.01 \quad(0.98-1.04)$ & $0.88 \quad(0.77-0.99)$ \\
\hline \multicolumn{3}{|c|}{ Adherence to chronic disease medications (reference $=$ few) } & Total hospitalization length of stay & $1.00(1.00-1.00)$ & $1.00 \quad(0.99-1.01)$ \\
\hline Adherent to most & $1.37 \quad(1.31-1.43)$ & $1.23(1.10-1.37)$ & Number of outpatient visits & $1.01 \quad(1.01-1.02)$ & $1.00 \quad(0.99-1.01)$ \\
\hline \multirow{2}{*}{$\begin{array}{l}\text { Not taking any chronic disease } \\
\text { medications }\end{array}$} & $1.22(1.15-1.30)$ & $1.02(0.89-1.19)$ & Number of unique hospitalizations & $0.99(0.98-1.00)$ & $1.01 \quad(0.99-1.02)$ \\
\hline & & & Postsurgical aortocoronary bypass & $0.94 \quad(0.76-1.16)$ & $1.37 \quad(0.88-2.14)$ \\
\hline \multirow{2}{*}{$\begin{array}{l}\text { Full statin adherence in baseline } \\
\text { period }\end{array}$} & $2.69(2.59-2.80)$ & $2.24(2.04-2.45)$ & Recent CABG & $1.28 \quad(0.73-2.25)$ & $0.34 \quad(0.09-1.28)$ \\
\hline & & & Previous CABG & $0.90 \quad(0.47-1.74)$ & $1.54 \quad(0.31-7.64)$ \\
\hline $\begin{array}{l}\text { Declining statin adherence in } \\
\text { baseline period }\end{array}$ & $1.17 \quad(1.13-1.22)$ & $1.00 \quad(0.90-1.11)$ & $\begin{array}{l}\text { Recent percutaneous coronary } \\
\text { intervention }\end{array}$ & $0.87 \quad(0.64-1.18)$ & $1.09 \quad(0.42-2.82)$ \\
\hline \multirow{2}{*}{$\begin{array}{l}\text { Female gender } \\
\text { Age }\end{array}$} & $0.92(0.89-0.97)$ & $0.91 \quad(0.84-0.99)$ & Previous percutaneous coronary & $0.81 \quad(0.59-1.12)$ & $1.23(0.48-3.12)$ \\
\hline & $1.01 \quad(1.01-1.01)$ & $1.00(1.00-1.01)$ & intervention & & \\
\hline \multirow{3}{*}{$\begin{array}{l}\text { Percentage of blacks in ZIP code } \\
\text { Percentage with high school } \\
\text { education or greater in ZIP code }\end{array}$} & $1.00(1.00-1.00)$ & $1.00(1.00-1.00)$ & Angina & $0.77 \quad(0.22-2.74)$ & - \\
\hline & $1.01 \quad(1.00-1.01)$ & $1.00(1.00-1.01)$ & Atrial fibrillation & $0.96 \quad(0.70-1.31)$ & $1.43 \quad(0.73-2.79)$ \\
\hline & & & Chest pain & $0.88 \quad(0.81-0.95)$ & $1.06 \quad(0.89-1.26)$ \\
\hline \multicolumn{3}{|c|}{ Median household income in ZIP code (reference $\leq \$ 50,000)$} & Congestive heart failure & $0.68 \quad(0.39-1.18)$ & $2.09(0.25-17.67)$ \\
\hline$\$ 50,000-\$ 99,999$ & $1.14(1.08-1.20)$ & $1.16 \quad(1.02-1.31)$ & Hypertension & $1.16 \quad(1.11-1.22)$ & $1.30 \quad(1.17-1.44)$ \\
\hline$\$ 100,000+$ & $1.37 \quad(1.27-1.48)$ & $1.487(1.26-1.76)$ & Ischemic heart disease & $1.14 \quad(1.06-1.23)$ & $1.14 \quad(0.97-1.33)$ \\
\hline Number of chronic conditions & $1.03(1.01-1.06)$ & $0.96 \quad(0.91-1.02)$ & Myocardial infarction & $0.81 \quad(0.56-1.18)$ & $4.14(0.51-33.45)$ \\
\hline \multicolumn{3}{|c|}{ Index statin } & Peripheral vascular disease & $1.22 \quad(0.87-1.70)$ & $0.76 \quad(0.41-1.40)$ \\
\hline \multicolumn{3}{|c|}{ Index statin generic (reference $=$ atorvastatin $)$} & Stroke & $0.90 \quad(0.62-1.32)$ & $1.26 \quad(0.37-4.35)$ \\
\hline Fluvastatin & $1.13 \quad(0.86-1.51)$ & $1.44(0.87-2.36)$ & Transient ischemic attack & $0.85 \quad(0.67-1.08)$ & $0.93 \quad(0.55-1.57)$ \\
\hline Lovastatin & $0.82(0.74-0.90)$ & $0.90 \quad(0.72-1.12)$ & COPD & $1.04(0.93-1.16)$ & $0.86(0.68-1.09)$ \\
\hline Pravastatin & $0.67(0.62-0.73)$ & $0.76(0.64-0.90)$ & Alzheimers & $0.80(0.59-1.07)$ & $1.01 \quad(0.51-2.02)$ \\
\hline Rosuvastatin & $0.80(0.76-0.86)$ & $0.84(0.74-0.96)$ & Depression & $1.00(0.92-1.09)$ & $0.84 \quad(0.69-1.02)$ \\
\hline Simvastatin & $0.80(0.76-0.86)$ & $0.84(0.74-0.95)$ & Cancer & $1.06(0.99-1.13)$ & $1.11 \quad(0.97-1.27)$ \\
\hline Pitavastatin & $0.53(0.40-0.69)$ & $0.67 \quad(0.33-1.37)$ & Diabetes & $1.08 \quad(1.02-1.15)$ & $(1.02-1.33)$ \\
\hline High-intensity dose & $1.00(0.94-1.05)$ & $1.02 \quad(0.91-1.15)$ & Kidney disease & $0.85(0.69-1.03)$ & $1.05 \quad(0.71-1.55)$ \\
\hline \multicolumn{3}{|l|}{ Copayment (reference $\leq \$ 6.40)$} & End-stage renal disease & $0.59(0.39-0.88)$ & $2.06 \quad(0.82-5.18)$ \\
\hline$\$ 6.40-\$ 14.99$ & $0.95 \quad(0.91-1.00)$ & $1.10 \quad(0.93-1.29)$ & Flu shot & $1.19(1.14-1.25)$ & $1.30 \quad(1.19-1.42)$ \\
\hline$\$ 15.00-\$ 34.99$ & $0.99 \quad(0.94-1.05)$ & $1.04(0.90-1.21)$ & Fecal occult blood test & $1.06 \quad(0.97-1.16)$ & $1.21 \quad(1.00-1.46)$ \\
\hline$\$ 35.00+$ & $0.85(0.80-0.91)$ & $0.97 \quad(0.83-1.12)$ & Mammography or PSA test & $1.15 \quad(1.09-1.22)$ & $1.10 \quad(0.98-1.23)$ \\
\hline
\end{tabular}

Our results also add to growing evidence that medication adherence is a complex behavior that cannot be explained well by health care use and clinical information recorded in administrative health care claims. Whereas the prevalent users in this study generally had higher adherence than the initiators studied by Franklin et al. (2016), the frequencies of individual adherence indicator patterns were similar. ${ }^{12}$ We also found that only pharmacy claims are needed to accurately predict future adherence. Models using medical claims alone achieved c-statistics below 0.60 , the threshold generally considered as moderate discriminative ability, and did not meaningfully improve discrimination in models with pharmacy claims-based predictors. In particular, the success of the 6 simple adherencebased pharmacy claims-derived predictors could form the basis of an intervention that could be easily implemented in a pharmacy or clinical outpatient setting. While postbaseline indicators alone were stronger predictors of future adherence, the information available through measurement of previous adherence also provided good discrimination. The former could be used in patients with no previous data history, whereas the latter could be implemented in settings where prediction or intervention is required without waiting for subsequent fills.

\section{Limitations}

This study has several limitations to consider. Study inclusion was restricted to patients who remained enrolled in commercial health insurance for at least 18 months, a group that may not be representative of all commercially insured patients or Medicare patients. This study focused on predicting adherence as measured in pharmacy claims data, which may misclassify the adherence of patients who fill prescriptions but do not actually take them. Finally, a known limitation of 
FIGURE 1 Percentage of Patients in Each Pattern of Post-index Statin Adherence Who Were Fully Adherent During Follow-up, Stratified by Pre-index Statin Adherence Among Those with an Index Fill $\leq 30$ Days Supply and $>30$ Days Supply
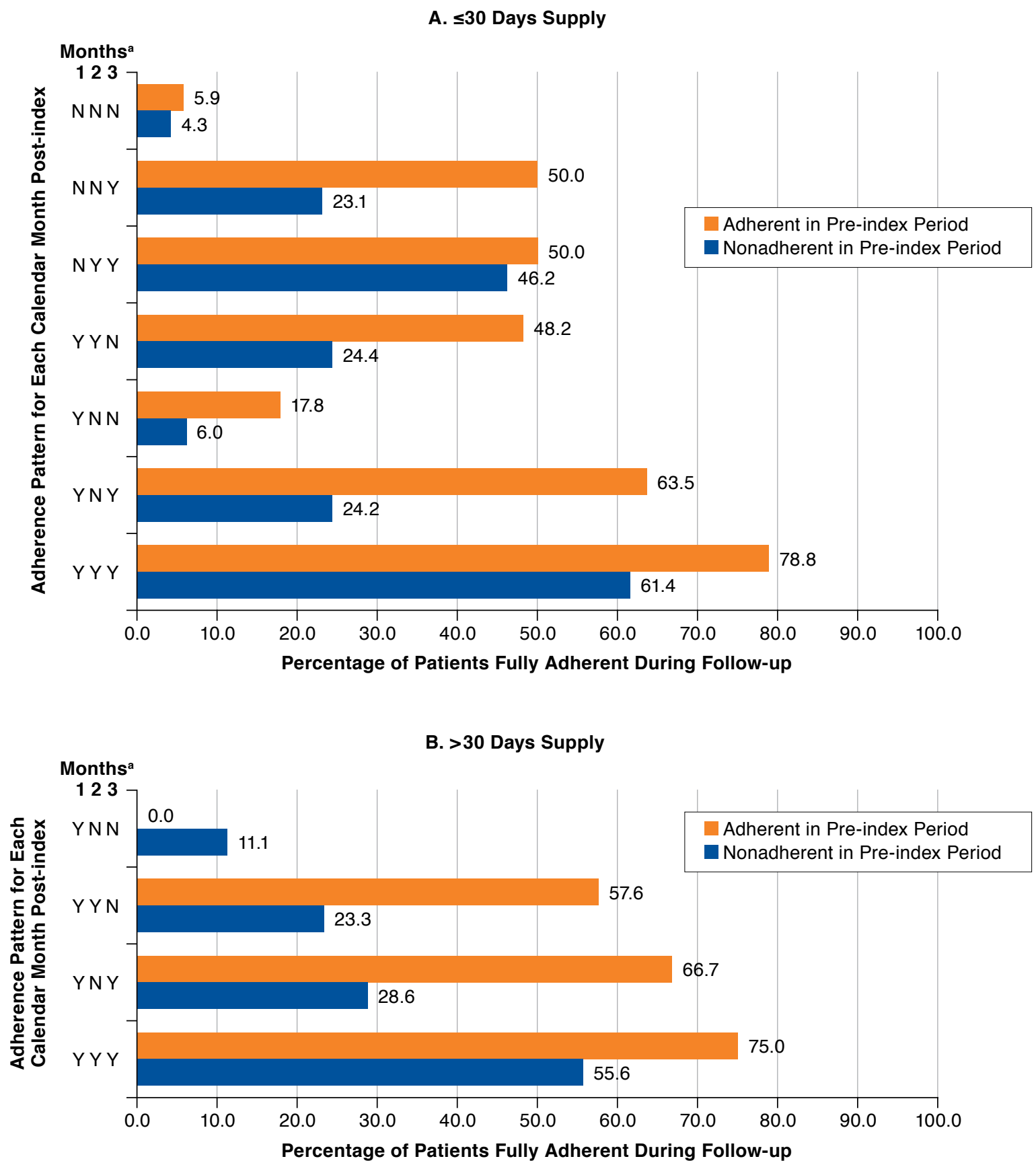

$a_{N}=P D C<0.80, Y=P D C \geq 0.8$ in that month.

$P D C=$ proportion of days covered. 
rank-based discriminative statistics such as the c-statistic is that discrimination may not improve with the addition of highly associated predictors if other highly associated predictors are already in the model. ${ }^{28}$

\section{Conclusions}

This analysis demonstrates the ability to predict adherence among prevalent medication users, who represent the majority of users at any given point, using adherence filling behavior before and immediately after an index prescription fill. Future research should evaluate whether these adherence behaviors can be used in more nuanced classifications of adherence behaviors, such as adherence trajectories, and across different therapeutic areas.

\section{Authors}

ALEXIS A. KRUMME, MS; JESSICA M. FRANKLIN, PhD; DANIELLE L. ISAMAN, BS; ANGELA Y. TONG, MS; and NITEESH K. CHOUDHRY, MD, PhD, Division of Pharmacoepidemiology and Pharmacoeconomics, Department of Medicine, Brigham and Women's Hospital and Harvard Medical School, Boston, Massachusetts. TROYEN A. BRENNAN, MD, JD, MPH; WILLIAM H. SHRANK, MD, MSHS; and OLGA S. MATLIN, PhD, CVS Health, Woonsocket, Rhode Island. CLAIRE M. SPETTELL, PhD, Data Science, Aetna, Hartford, Connecticut.

AUTHOR CORRESPONDENCE: Niteesh K. Choudhry, MD, PhD, Brigham and Women's Hospital, Harvard Medical School, 1620 Tremont St., Ste. 3030, Boston, MA 02120. Tel.: 617.278.0930; E-mail:nkchoudhry@bwh.harvard.edu.
3. Choudhry NK, Setoguchi S, Levin R, Winkelmayer WC, Shrank WH. Trends in adherence to secondary prevention medications in elderly post-myocardial infarction patients. Pharmacoepidemiol Drug Saf. 2008;17(12):1189-96

4. DiMatteo MR, Giordani PJ, Lepper HS, Croghan TW. Patient adherence and medical treatment outcomes: a meta-analysis. Med Care. 2002:40(9):794-811

5. Roebuck MC, Liberman JN, Gemmill-Toyama M, Brennan TA. Medication adherence leads to lower health care use and costs despite increased drug spending. Health Aff (Millwood). 2011; 30(1):91-99.

6. Dean AJ, Walters J, Hall A. A systematic review of interventions to enhance medication adherence in children and adolescents with chronic illness. Arch Dis Child. 2010;95(9):717-23.

7. Haynes RB, Ackloo E, Sahota N, McDonald HP, Yao X. Interventions for enhancing medication adherence. Cochrane Database Syst Rev. 2008;(2):CD000011.

8. Morgado MP, Morgado SR, Mendes LC, Pereira LJ, Castelo-Branco M. Pharmacist interventions to enhance blood pressure control and adherence to antihypertensive therapy: review and meta-analysis. Am J Health Syst Pharm. 2011;68(3):241-53.

9. Ogedegbe GO, Boutin-Foster C, Wells MT, et al. A randomized controlled trial of positive-affect intervention and medication adherence in hypertensive African Americans. Arch Intern Med. 2012;172(4):322-26.

10. Raymond CB, Morgan SG, Katz A, Kozyrskyj AL. A population-based analysis of statin utilization in British Columbia. Clin Ther. 2007;29(9):2107-19.

11. Centers for Medicare \& Medicaid. Trends in Part $C \& D$ star rating measure cut points. 2014. Available at: https://www.cms.gov/medicare/prescription-drug-coverage/prescriptiondrugcovgenin/downloads/2014-trends-inpart-c-and-d-star-rating-measure-cut-points.Pdf. Accessed March 3, 2017.

12. Franklin JM, Shrank WH, Lii J, et al. Observing versus predicting: initial patterns of filling predict long-term adherence more accurately than high-dimensional modeling techniques. Health Serv Res. 2016;51(1):220-39.

13. Brookhart MA, Patrick AR, Dormuth C, et al. Adherence to lipid-lowering therapy and the use of preventive health services: an investigation of the healthy user effect. Am J Epidemiol. 2007;166(3):348-54.

14. Rassen JA, Glynn RJ, Brookhart MA, Schneeweiss S. Covariate selection in high-dimensional propensity score analyses of treatment effects in small samples. Am J Epidemiol. 2011;173(12):1404-13.

15. Schneeweiss S, Rassen JA, Glynn RJ, Avorn J, Mogun H, Brookhart MA. High-dimensional propensity score adjustment in studies of treatment effects using health care claims data. Epidemiol Camb Mass. 2009;20(4):512-22.

16. Choudhry NK, Glynn RJ, Avorn J, et al. Untangling the relationship between medication adherence and post-myocardial infarction outcomes: medication adherence and clinical outcomes. Am Heart J. 2014;167(1):51-58.e5.

17. Pharmacy Quality Alliance. PQA performance measures. Available at: http://pqaalliance.org/measures/default.asp. Accessed March 3, 2017.

18. National Committee for Quality Assurance. Summary table of measures, product lines and changes. HEDIS 2014, volume 2. Available at: http:// www.ncqa.org/Portals/0/HEDISQM/HEDIS2014/List\%20of\%20HEDIS\%20 2014\%20Measures.pdf. Accessed March 3, 2017.

19. Fava GA. Can long-term treatment with antidepressant drugs worsen the course of depression? J Clin Psychiatry. 2003;64(2):123-33.

20. Efron B, Gong G. A leisurely look at the bootstrap, the jackknife, and cross-validation. Am Stat. 1983;37(1):36-48

21. Harrell FE, Lee KL, Mark DB. Multivariable prognostic models: issues in developing models, evaluating assumptions and adequacy, and measuring and reducing errors. Stat Med. 1996;15(4):361-87.

22. Steyerberg EW, Harrell FE, Borsboom GJ, Eijkemans MJ, Vergouwe Y, Habbema JD. Internal validation of predictive models: efficiency of some procedures for logistic regression analysis. J Clin Epidemiol. 2001;54(8):774-81. 
23. King AC, Frey-Hewitt B, Dreon DM, Wood PD. Diet vs exercise in weight maintenance. The effects of minimal intervention strategies on long-term outcomes in men. Arch Intern Med. 1989;149(12):2741-46.

24. Smart N, Haluska B, Jeffriess L, Marwick TH. Predictors of a sustained response to exercise training in patients with chronic heart failure: a telemonitoring study. Am Heart J. 2005;150(6):1240-47.

25. Look AHEAD Research Group, Wing RR. Long-term effects of a lifestyle intervention on weight and cardiovascular risk factors in individuals with type 2 diabetes mellitus: four-year results of the Look AHEAD trial. Arch Intern Med. 2010;170(17):1566-75.
26. Kanning M. Physically active patients with coronary artery disease: a longitudinal investigation of the processes of exercise behaviour change. Br J Health Psychol. 2010;15(Pt 3):583-97.

27. Franklin JM, Krumme AA, Shrank WH, Matlin OS, Brennan TA, Choudhry NK. Predicting adherence trajectory using initial patterns of medication filling. Am J Manag Care. 2015;21(9):e537-544.

28. Cook NR. Use and misuse of the receiver operating characteristic curve in risk prediction. Circulation. 2007;115(7):928-35. 
Predicting 1-Year Statin Adherence Among Prevalent Users: A Retrospective Cohort Study

\section{APPENDIX A Cross-Validated C-Statistics, All Models}

\begin{tabular}{|c|c|c|c|c|c|c|c|c|c|}
\hline Model & $\begin{array}{l}\text { Investigator- } \\
\text { Specified } \\
\text { Pharmacy and } \\
\text { Demographic }\end{array}$ & $\begin{array}{l}\text { Pre-index } \\
\text { Adherence }\end{array}$ & $\begin{array}{c}\text { Pharmacy } \\
\text { Claims hd-PS }\end{array}$ & $\begin{array}{l}\text { Investigator- } \\
\text { Specified } \\
\text { Medical } \\
\end{array}$ & $\begin{array}{c}\text { Medical } \\
\text { Claims hd-PS }\end{array}$ & $\begin{array}{c}\text { Observation } \\
\text { of Post-index } \\
\text { Filling }\end{array}$ & Full Cohort & $\begin{array}{c}\leq 30 \text { Days } \\
\text { Supply }\end{array}$ & $\begin{array}{c}>30 \text { Days } \\
\text { Supply }\end{array}$ \\
\hline 1 & $\mathrm{x}$ & & & & & & 0.60 & 0.60 & 0.56 \\
\hline 2 & & $\mathrm{x}$ & & & & & 0.70 & 0.71 & 0.59 \\
\hline 3 & $\mathrm{x}$ & $\mathrm{x}$ & & & & & 0.71 & 0.72 & 0.61 \\
\hline 4 & & & $\mathrm{x}$ & & & & 0.60 & 0.58 & 0.52 \\
\hline 5 & $\mathrm{x}$ & & $\mathrm{x}$ & & & & 0.63 & 0.65 & 0.55 \\
\hline 6 & $\mathrm{x}$ & $\mathrm{x}$ & $x$ & & & & 0.71 & 0.73 & 0.60 \\
\hline 7 & & & & $\mathrm{x}$ & & & 0.57 & 0.57 & 0.56 \\
\hline 8 & & & & & $\mathrm{x}$ & & 0.57 & 0.57 & 0.55 \\
\hline 9 & & & & $\mathrm{x}$ & $\mathrm{x}$ & & 0.58 & 0.58 & 0.56 \\
\hline 10 & $\mathrm{x}$ & $\mathrm{x}$ & $\mathrm{x}$ & $\mathrm{x}$ & $\mathrm{x}$ & & 0.72 & 0.73 & 0.60 \\
\hline 11 & & & & & & $\mathrm{x}$ & 0.74 & 0.76 & 0.49 \\
\hline 12 & $\mathrm{x}$ & $\mathrm{x}$ & & & & $\mathrm{x}$ & 0.78 & 0.80 & 0.61 \\
\hline 13 & $\mathrm{x}$ & & $\mathrm{x}$ & & & $\mathrm{x}$ & 0.77 & 0.79 & 0.55 \\
\hline 14 & & $\mathrm{x}$ & & & & $\mathrm{x}$ & 0.78 & 0.80 & 0.60 \\
\hline 15 & $\mathrm{x}$ & $\mathrm{x}$ & $\mathrm{x}$ & & & $\mathrm{x}$ & 0.78 & 0.80 & 0.60 \\
\hline 16 & & & & $\mathrm{x}$ & & $\mathrm{x}$ & 0.76 & 0.78 & 0.57 \\
\hline 17 & $\mathrm{x}$ & $\mathrm{x}$ & $\mathrm{x}$ & $\mathrm{x}$ & $\mathrm{x}$ & $\mathrm{x}$ & 0.79 & 0.80 & 0.60 \\
\hline
\end{tabular}


Predicting 1-Year Statin Adherence Among Prevalent Users: A Retrospective Cohort Study

APPENDIX B Cross-Validated C-Statistics for Main Models, January Index Verus May Index Cohorts

\begin{tabular}{|c|c|c|c|c|c|c|c|}
\hline Model & Predictors & $\begin{array}{c}\text { All Users } \\
\text { January } \\
\text { Cohort }\end{array}$ & $\begin{array}{l}\text { All Users } \\
\text { May } \\
\text { Cohort }\end{array}$ & $\begin{array}{c}\leq 30 \text { Days } \\
\text { Supply } \\
\text { January } \\
\text { Cohort }\end{array}$ & $\begin{array}{c}\leq 30 \text { Days } \\
\text { Supply } \\
\text { May } \\
\text { Cohort }\end{array}$ & $\begin{array}{c}>30 \text { Days } \\
\text { Supply } \\
\text { January } \\
\text { Cohort }\end{array}$ & $\begin{array}{c}>30 \text { Days } \\
\text { Supply } \\
\text { May } \\
\text { Cohort }\end{array}$ \\
\hline 1 & $\begin{array}{l}\text { Investigator-specified pharmacy and } \\
\text { demographic }\end{array}$ & 0.60 & 0.60 & 0.60 & 0.61 & 0.56 & 0.58 \\
\hline 2 & Pre-index adherence & 0.70 & 0.69 & 0.71 & 0.70 & 0.59 & 0.58 \\
\hline 3 & Pharmacy claims hd-PS & 0.60 & 0.59 & 0.58 & 0.62 & 0.52 & 0.52 \\
\hline 4 & All pharmacy and demographic & 0.71 & 0.71 & 0.73 & 0.73 & 0.60 & 0.59 \\
\hline 5 & Investigator-specified medical & 0.57 & 0.55 & 0.57 & 0.55 & 0.56 & 0.55 \\
\hline 6 & Medical claims hd-PS & 0.57 & 0.55 & 0.57 & 0.54 & 0.55 & 0.52 \\
\hline 7 & All pharmacy, demographic, and medical & 0.72 & 0.71 & 0.73 & 0.72 & 0.60 & 0.57 \\
\hline 8 & Observation of post-index filling & 0.74 & 0.77 & 0.76 & 0.80 & 0.49 & 0.49 \\
\hline 9 & $\begin{array}{l}\text { Pre-index adherence }+ \text { observations of } \\
\text { post-index filling }\end{array}$ & 0.78 & 0.80 & 0.80 & 0.83 & 0.60 & 0.58 \\
\hline 10 & $\begin{array}{l}\text { All pre-index pharmacy, demographic, and } \\
\text { medical + observation of post-index filling }\end{array}$ & 0.79 & 0.81 & 0.80 & 0.83 & 0.60 & 0.57 \\
\hline
\end{tabular}

